\title{
Networked and Digitally Based Actions for Citizen-centered Design: Transparency Hacker, a Case Study
}

\author{
- Daniela Kutschat Hanns \\ LabVisual | FAUUSP, Brazil \\ dk.hanns@usp.br
}

\begin{abstract}
Transparência Hacker (Transparency Hacker or THacker), a community that promotes a variety of online and offline actions designed to open up public data resources to citizens and to encourage citizens participation in civil rights and law-making. In this paper THacker acts as a case study of projects focused on social innovation within the context of eGovernment, open data and transparency.
\end{abstract}

Keywords: Civic Participation, Transparência Hacker, Open Data, eGovernment

\section{Introduction}

In a digital network based society, community focused actions are often promoted in a collaborative and participatory way. If in the past the divisions between public and private data sourcing were well defined, today they are increasingly based on participatory principles: smartphone users, for example, tend to provide information on a voluntary basis. One shares information about location, habits and thoughts. We download a plethora of apps which are gateways for robust systems that track who you are, what you do, what you like and what you dislike. On one hand, this kind of information is widely used for sales and marketing. On the other, it can be helpful for pattern recognition analysis of flows, groups and individuals. It can assist in the monitoring of a city, and it can assist citizens in their daily tasks. It can also be used to improve city management.

Focused on city improvement and civic participation, these changes are also motivated by a collaborative and participatory approach seen these days around the globe, which is often promoted by digitally based social networks. Since 2013 the authors have conducted research into Brazilian networks, which include services, apps and products for citizens and civic participation. At the moment we are examining collaborative actions that involve collectives, startups, individuals and government bodies.

In several countries, the ability of federal, state and local governments to plan, act and collaborate on urban problems and solutions that affect citizens is limited by budget constraints, political disputes, and a lack of management at various levels, among other factors. People often can't rely on the government for vital issues such as information, governance, health assistance and sanitation, to name a few. Experience in many countries has shown that digital technologies (through apps, services and social networks) have had a huge impact on this situation, and this has led individuals and governments to act together on relevant issues dealing with monitoring, sharing and proposing solutions.

Transparência Hacker (THacker) is a community which promotes a wide variety of online and offline actions designed to open up public data resources to citizens and encourage participation in civic, civil rights and law making issues. When we began our research in 2013, this group had around one a thousand members; by September 2015 this number had risen to 1,786. The group has shown itself to be emblematic and unique in acting as an emergent system built by people who are focused on public transparency and enhancing citizen rights and collaborating with government bodies to spread the application of rights and laws.

\section{THacker as a case study}

To study the THacker community, we have used sources 
that include the websites W3C, Open Government Data (OGD), Portal Brasileiro para Dados Abertos (the Brazilian Portal for Open Data) and other online government platforms. In the same manner, we have also consulted the nation's laws as well as articles and specific sections of our Constitution. Another source has been the google group that serves as a forum and online communications platform for the THacker community, which today is made up of people from all walks of life living in cities throughout the country. All these participants share an interest in the transparency of public data and actions that can be taken, based on the principles of collaboration and sharing, which aim to spread the awareness of and encourage the exercise of citizens' rights. Other relevant sources are offline actions, as well as programs, apps and websites that make up part of the community's online actions. In this article, the THacker community's actions will be analyzed to point out how their principles and their loyalty to a sense of community permeate their activism and the way they interact with the government. Legislation, open data, transparency and hacker activism are elements of the proposed approach based on authors as Holzner \& Holzner (2006) and Darbishire (2009), who discuss Open Data and Proactive Transparency. Aló (2009), Capelli, Leite \& Araújo (2010), Braga (2011), Felix \& Handorf (2011) and Silva (2011) contribute in highlightening approaches about transparency in organizations and withinh the Brazilian eGovernment context.

\section{First Transparency Hacker Day}

Made up of programmers, journalists, designers, and public managers, among others, the origin of the THacker community dates back to the first Transparency Hacker Day, which was held in October 2009 at Casa da Cultura Digital (CCD - The House of Digital Culture), at Rua Vitorino Carmilo 453 in the neighborhood of Santa Cecília in São Paulo. CCD brought together individuals, organizations and companies in a collective group with the shared mission of using technology for social ends. This mission encompassed projects, work and various actions that were to be taken. At the time, the 'think and do' tank Esfera - Hacks Politicos e Dados Abertos (Sphere - Political Hacking and Open Data), a company located at house number 2 of the complex run by Pedro Markun and Daniela Silva, posted the program on its website. The objective of the meeting was to promote political discussion through collaboration and actions taken on the internet. According to the program, it was to be: "A challenge focused on accessing governmental information and public data through web tools and using them to increase the public's political participation on the internet and to make government management more transparent" [MARKUN \& SILVA, 2009].

Around 120 people participated in the meeting. Results of the meeting included apps and feed (rss) to follow voting in Congress, a mashup to compare deforestation data about the Amazon, and a map to identify the demand for adult schools.

Another important result was the participants' signing up to be members of an open shared platform online, a google group. Used as a forum, it remains in operation to this day as a virtual meeting place which serves as a formal location for THacker members to discuss actions and exchange ideas.

\section{THacker, open data and laws}

It's important to emphasize that THacker arose at a time when the federal government, the state governments and municipal governments had the communication and dissemination of government data, government actions and transparency on their agendas. At the time much of the effort of the THacker activists went into making government accessible data more accessible to the average citizen. A secondary objective was that this data, once transformed into comprehensible information, would raise public consciousness about issues affecting citizens and their civil rights.

Markun (2012) describes the initial motivations of THacker: "We began with a series of talks, mainly motivated by W3C [an international consortium that develops web standards], focused on the Law of Access (to Public Information). In my case, this greater involvement in politics had to do with the election of (Gilberto) Kassab (as Mayor) in São Paulo (in 2008). I was complaining in a bar, and it occurred to me that I hadn't done anything to change things. It wasn't that I had a better candidate to present, but just complaining was a poor option."

According to Markun, the guiding principles in terms of open data were aligned with the discussions and publications made by W3C (the World-Wide Web Consortium). They were elaborated in a five star model by Tim Berners-Lee in 2006. To Berners-Lee, open data should meet five requirements that he placed on a scale from one to five stars [Figure 1]: 1. open license; 2. machine-readable data; 3. a non-proprietary format; 4. using open data standards; 5. linking to other open data websites to provide context.

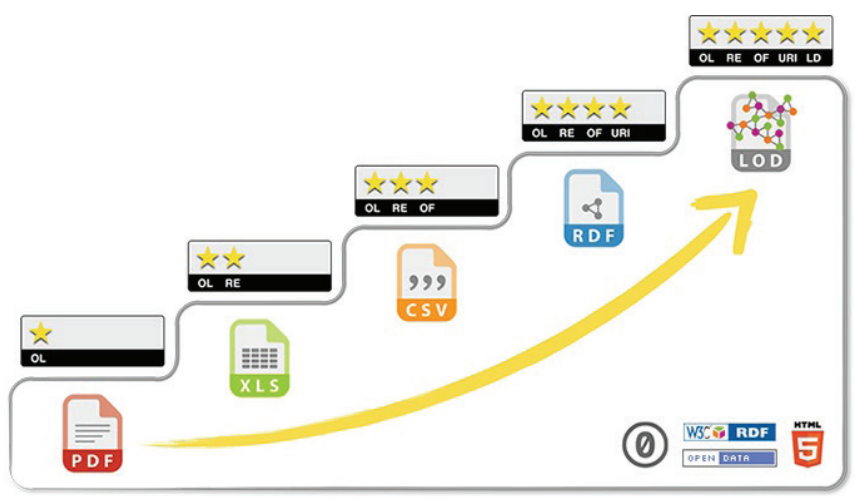

Figure 1: Five star deployment scheme. Berners-Lee (2006).

Half a year later, a working group at Open Government Data, located in the United States, published 8 principles for open data (The Annotated 8 Principles, 2007): stating that it must be 1. complete, available, and not subject to valid privacy, security or privilege limitations; 2 . Primary, with data appearing as collected at its source, with the highest possible 
level of granularity, not in aggregate or modified forms; 3. timely, made available as quickly as necessary to preserve the value of the data; 4 . accessible, available to the widest range of users for the widest range of purposes; 5 . machine processable, reasonably structured to allow automated processing; 6. non-discriminatory, available to anyone, with no requirement of registration; 7. non-proprietary, available in a format over which no entity has exclusive control; 8. license-free, not subject to any copyright, patent, trademark or trade secret regulation. Reasonable privacy, security and privilege restrictions may be allowed. Later the activist and Canadian government consultant David Eaves (2009) presented three laws for open data known as find, use, and share. They're based on the following principles: 1 . if it can't be spidered or indexed, it doesn't exist; 2 . if it isn't available in open and machine readable format, it can't engage; 3. if a legal framework doesn't allow it to be repurposed, it doesn't empower. It's important to remember that these rules, models and principles were rapidly disseminated throughout the world among programming communities and internet activists such as THacker.

According to Lira and Svab (2012), one of THacker's earliest achievements together with the Brazilian federal government was the establishment of article $8^{\circ} \S 3^{\circ}$, which guarantees open data access that is non-proprietary and machine-readable under Common Law 12,527/ 2011, which regulates access to information under Section XXXIII of article $5^{\circ} \S 3^{\circ}$ of the federal Constitution.

The engagement of members of THacker with the federal government led to the establishment of the Open Data Portal, also in 2011, which was a further consequence of this initiative. The three principles presented by Eaves and the eight principles of OGD are cited in the portal's presentation as well as the goals behind its creation: 1 . to make government more transparent; 2 . to help society contribute to innovative services available to its citizens; 3 . to improve the quality of government data; 4 . to make new businesses viable and 5 . to make it required by law.

Today government bodies and organizations linked to the government usually produce reports and financial reports in accessible formats, but six years ago the situation was different. Thus we should note that making public data more accessible to its citizens was one of Transparência Hacker's stated missions. After the approval of the Public Information Access Law in 2011, Thacker organized a Hackday in partnership with the Open Knowledge Foundation (OKNF) to adapt the British "What Do They Know", produced by MySociety. The Brazilian version, "We Want to Know" (Queremos Saber, 2011), is designed to assist citizens in requesting information to a government body and in becoming feedback from this body. Once the request is sent, the body is required to respond within 20 days. Since everything is registered, citizens can consult what has already been requested to avoid repetition, follow requests and receive information. If the government body doesn't provide answer within 20 days, the system sends a message informing citizen and government body, acting as a supervisor. The site won the Mario Covas Award for Open Government in 2013 [Figure 2, left].

Websites created by participants of THacker to be information sources for citizens won other national and international innovation prizes. Deciphering the São Paulo City Council (Decodificando a Câmara de São Paulo, 2011), sponsored by Rockefeller Foundation, a website project to show bills proposed by aldermen of São Paulo's city council and to allow citizens to follow the vote, won the Innovation Challenges Competition (ICC 2012) wasn't implemented. Rockefellers Foundation site presentes the Brazilian Digital Culture Laboratory of São Paulo as winning organization. Its site is inactive, but it can be found at Hacker Laboratory São Paulo website (http://labhacker.org.br/). Its description tells that it was founded in 2008 to "articulate and fortify digital culture in Brazil to share knowledge and codes and to disseminate openness and transparency as world changing practices". One can find one of Pedro Markuns posts (2014) on the laboratorys google group explaining that this Lab is reactivation of the former CCD.

Other websites, as Keeping an Eye on the Amendments (De Olho nas Emendas), Adopt a Request (Adote um Pedido) and Portrait of Violence (Retrato da Violência) won three prizes of the Open Data for Development (OD4D) section of ICC 2012.

The website SP Flooding (Alagamentos SP, 2011), which organizes data collected by the flooding control and monitoring government body of São Paulo city was adopted as an organized data ressource by this body [Figure 2, centre]. Shacks on Fire (Fogo no Barraco, 2012) shows possible relations between fire occurences in poor neighborhoods and immobiliary speculation emerging on these areas [Figure 2, right].

Lambe-Lambe was an online service until 2014 [Figure 3, left]. One could print posters comparing two public investment areas of one Brazilian state to be displayed in public spaces or shared via facebook. The figure shows that the state government of Acre invested less in social assistance than in commerce and services. Hacked SACSP [Figure 3, right] was an action to reveal statistics of citizens' complaints of São Paulo state cities customer services ranked by government agency .

A year later, initiatives like the websites De Olho nas Emendas (Keeping an Eye on the Amendments), Adote um Pedido (Adopt a Request) and Retrato da Violência (Portrait of Violence) won three prizes in the Open Data for Development (OD4D) section at the same event. 


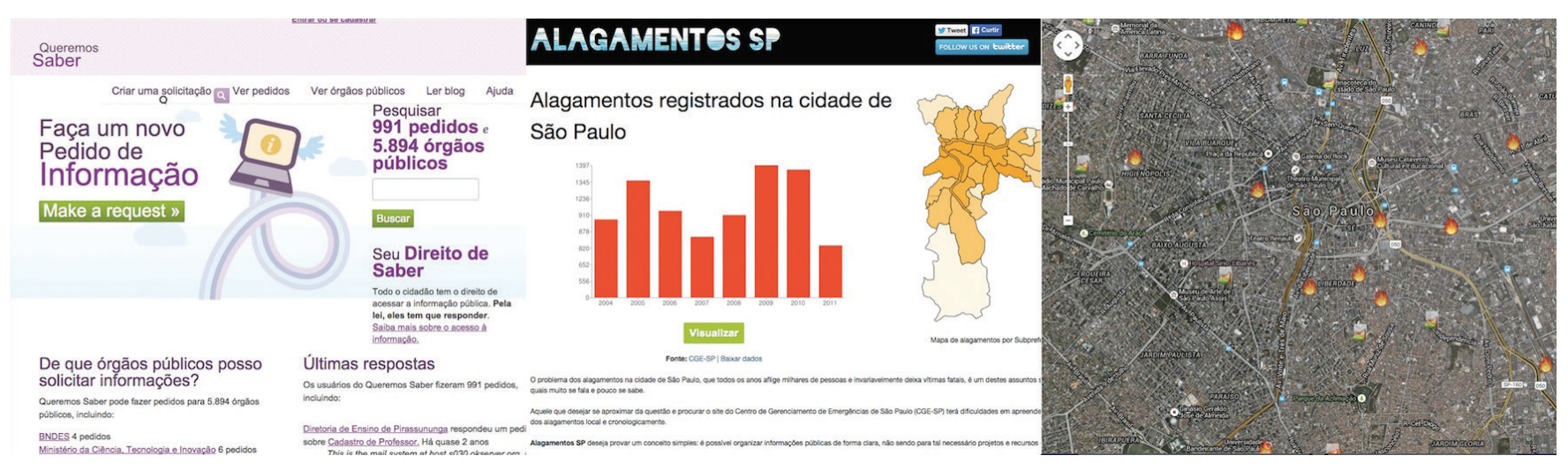

Figure 2: Snapshots. Websites by THacker. Left: We Want to Know, 2011. Centre: SP Flooding, 2011. Right: Shacks on Fire, 2012.

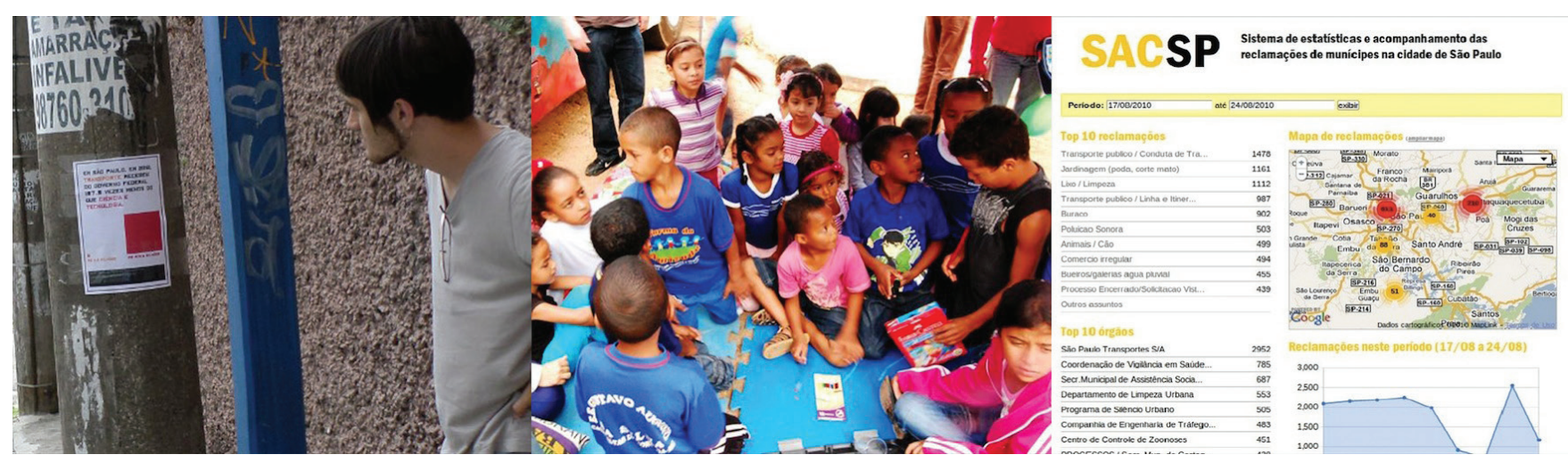

Figure 3: Snapshots. Websites by THacker. Left: Lambe-Lambe, 2013. Centre: Hacker Bus action, 2012. Right: Hacked SACSP, 2011.

\section{THacker, transparency and e-government}

Considering transparency in a global context, Holzner and Holzner (2006) state that transparency is the social value placed on openness and being public or the degree to which authorities reveal information. To Braga (2011) transparent management means government bodies that make their actions and related data accessible to the public at large. He cites Silva (2010), "(...) in some way, all human actions are surrounded by real instruments which make transparency and fiscal and social control possible. In this manner, the presence of Government Power in almost all of our daily activities has brought the citizen closer to the State, in part due to the transparency of control mechanisms, and also through the actions and reactions of its citizens which treat this as a social right." (14). To Silva (2011) to be more effective, the Brazilian governments transparency has to ally budget execution control to the correspondent federal policy results. Furthermore, the author views state and society relations as an endeavor of a sharing responsibilities perspective.

Felix and Handorf (2011) refer to Darbishire (2009) to describe the promotion of transparency via the internet: "However, to promote transparency with the use of the internet we need to know what information is needed and for what purpose. In this sense, Darbishire (2009) shows that the drivers of proactive transparency are: i) the need to inform the public about laws and decisions and the public's right to be informed, to know their rights and obligations; ii) the public's demand for the information needed to hold governments accountable both during and between elections - how they spend public funds; iii) the demand for information in order to participate actively in decision-making - it can change the way public policies are developed, reducing capture by special interest groups; and iv) the provision to the public of information needed to access government services, which has expanded significantly in the past decade with the growth of electronic access to services or ?egovernment." (7).

Darbishire (2009), in turn, emphasizes that government strategies for the active disclosure of information (in the absence of citizen requirements or demands) in countries with relatively low internet access should not use the internet as a substitute for other forms of communication: "E-government should not, however, replace existing disclosure modes in countries with low Internet penetration. Conventional channels, notice boards, informative leaflets, radio, television, and public meetings or the use of mobile phones where relevant, permit the public to learn about services and subventions in areas such as health, education, employment, agriculture, and business, thereby contributing to human and economic development."(14).

Aló (2009) and Cappelli \& Leite (2008) argue, through studies and models, that advances in organizational transparency have created a need for specific models to evaluate and verify degrees of transparency. The most recent model used by Capelli, Leite \& Araújo $(2010,101)$ presents 
criteria to measure transparency such as: a) the number of people that can access the data; b) it's usability; c) the quality of the information; d) how easily it may be understood and e) the auditability of available data.

Complementary Law131/2009 of theFiscal Responsibility Law, passed on May 27, 2009, determines that detailed federal, state, and city budget and financial information should be made available in real time. As the collective's name indicates, transparency defines THacker's mission. The posts, writings and interviews with the THacker community show that they share a common purpose, namely to guarantee transparency and access to government information. Another important issue to them is the disclosure of information about government actions that affect civil rights. An information sharing mechanism provides the structure for preparing actions (on and outside of the internet) designed to raise public awareness and further the exercise of the public's rights. The community and its members act as references for NGO and government projects, such as Observatório da Educação or OE (Education Observatory), Open Knowledge Brasil (OKB), Banco Nacional do Desenvolvimento Transparente (Transparent National Bank of Development), Controladoria Geral da União (the Federal Office of the Controller) and the Secretaria Nacional de Justiça do Ministério da Justiça (National Justice Secretariat of the Ministry of Justice). This partnership is instrumental to this activism, and there's cooperation between individuals and government bodies in the pursuit of following international transparency protocols, actions close to citizens, education and training.

With the establishment of an online google group after the first Transparency Hacker Day, people from various states and cities joined the THacker community. THackers' posts concern subjects as transparency of government data and related competitions, congresses, courses, talks and job opportunities. The forum also comments on and promotes initiatives (apps, websites and data sharing) and collectives focused on activism and civil rights.

\section{THacker and hackactivism}

It should be remembered that in 2009 much of the government's public data was presented in lists that were difficult to read and understand, appearing to be written in code to the ordinary citizen. This reality gives an appropriate context to the atmosphere of hacker activism that appears in the THacker community's webpage: "We're hacking the politics that we know today, to make them more open and participative through collaboration and internet action. This is a space dedicated to the proposal and articulation of ideas and projects that use technology for social ends, mainly open government data, transparency, freedom of information and freedom of expression. During this process, THacker received support from W3C (World Wide Web Consortium) to expand and create projects (...)" (MARKUN \& SILVA, 2009). Starting with such a focused mission, it has managed to surpass all the other projects that we've tracked over the last two years.
If we consider the THacker forum (google group) as a source of information about the community, we can see, for example, who are the most active members in the forum. Over the past two years, we have noted that there are some actions that receive little coverage, but have had important consequences. One THacker initiative for "hacking" data is the blog http://thacker.diraol.eng.br/ferramentas/ which offers options for programming as well as access and data manipulation.

However, it appears to us that this blog was constructed for a onetime event and has not been maintained because it has already served its purpose, as has been the case with other initiatives. We observe here that there are posts about an action, this being but one of several examples, yet there are no posts about the reason behind the action, its development or repercussions. Thus, the google group serves as a place to get in touch with each other, but when members decide to work on a project, they must be using another form of communication. Thus, it's necessary to search for actions outside of this forum and even outside the internet. In this sense, hacker activism is not restricted to digital media.

At this point, it's important to note that THacker activities helped create two laboratories with ties to governmental bodies called Hacker Laboratories (LabHacke). They're spaces dedicated to developing projects related to topics as laws and rights open to anyone. As we have seen before, THacker discussed laws, as the Information Law and members maintained communication with government bodies [Figure 4].

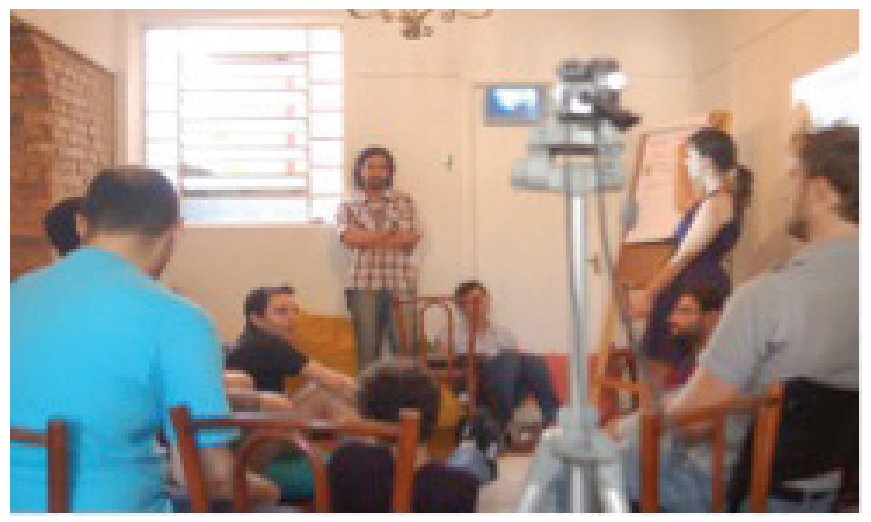

Figure 4: THacker discussing the Information Law, 2011.

In May 2012 São Paulo City Council invited THacker to organize the first City Council Hackathon. Citizens, NGOs and collectives (and their representatives) collaborated to create websites and apps with public government data. In October 2013, the House of Representatives in Brasilia received help from THacker in the organization of the first Hacker Marathon, an initiative which sought to promote interaction between congressmen, hackers, public servants and ordinary citizens. After and during the event, the themes of posts on the THacker forum were related to data use, data security and privacy; the use of platforms and free software; 
and the creation of a participative posting structure. Content posted included meeting notes, streaming videos and photos. In the interaction between collectives, civil participants and government members in Brasília, THacker asked the House Speaker to make the event's format permanent. A few months later, LABHacker was instituted in Brasília [Figure 5].

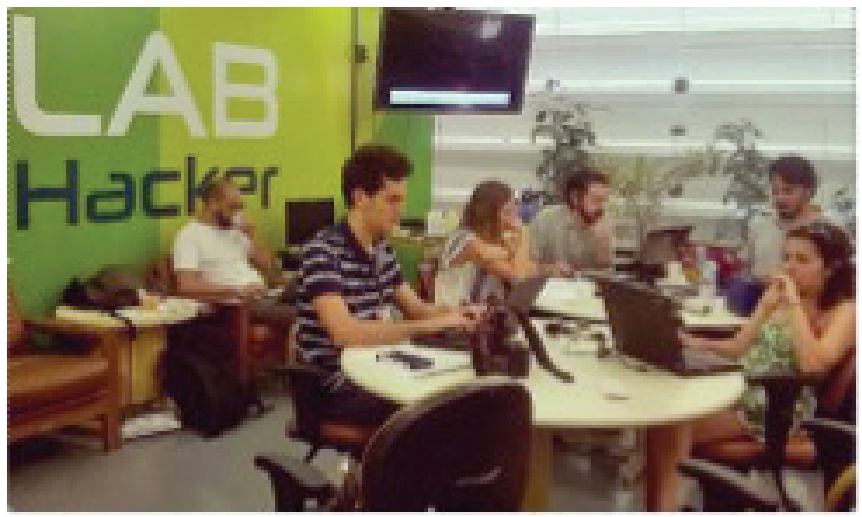

Figure 5: LABHacker. House of the Representatives. Brasília,2013.

The lab's website declares: "The first programmers and technology enthusiasts who got together to interact and develop creative solutions driven by the great revolution in personal computing called themselves hackers. Civic hackers, for example, are concerned with civic participation and the principles of collaboration and sharing." There is no signature indicating the author of this text, thus we do not know which voices this document represents.

\section{THacker in action}

After the approval of the Public Information Access Law in 2011, THacker organized a Hackday in partnership with the Open Knowledge Foundation (OKNF) to adapt the British What Do They Know program, produced by MySociety, to Brazil. The Brazilian version entitled Queremos Saber (We Want to Know) is designed to assist citizens in requesting information from government bodies and getting feedback from these bodies. Once the request is sent, the government body is required to respond within 20 days. Since everything is registered, citizens can consult what has already been requested to avoid repetition, follow the progress of requests and receive information. If the government body doesn't provide an answer within 20 days, the system sends a message informing the citizen and the government body, and it acts as a supervisor in this process.

According to Liane Lira (2013), in a talk given at the TEDxUFG Conference, Ônibus Hacker (Hacker Bus) arose as a creative environment and laboratory when members of THacker organized crowdfunding for it using the website Catarse and raised almost 60 thousand reais from over 400 people in a period of two months.

Ônibus Hacker (Hacker Bus) began its operations as a movable space which promotes workshops, urban interventions and speeches and helps disseminate hacker culture and collaboration to raise public awareness and improve local conditions. It is being used as a vehicle by volunteer members of the group to inform citizens in small municipalities of the existence of an organic law that permits any bill to become law if $5 \%$ of the signatures of the local electorate are collected. Besides raising public awareness, it offers workshops so that citizens can follow the process using social networks. The bus is also used to promote events where citizen rights and political participation in the digital age are discussed [Figure 2, Centre and Figure 6].

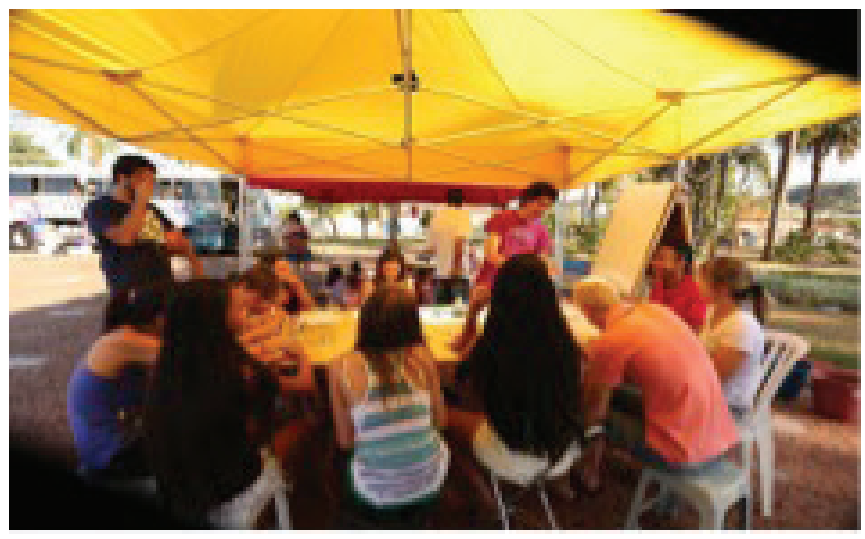

Figure 6: Hacker Bus. Law Workshop in Gavião Peixoto, 2015.

Theactivities of Ônibus Hacker (Hacker Bus)areorganized through a google group similar to the THacker group: it's decentralized, open, and only the first post is filtered (to prevent spam). At the time of this writing, the Ônibus Hacker group has 209 members and 1,224 topics. The blog http:// onibushacker.org/ publishes its activities. It's currently out of date given that the last post dates from September last year and there have been group posts in the forum covering more than 300 topics between January and August this year. In the blog's comment area, there are posts from many interested Brazilians, Uruguayans, and Italians. There are suggestions, doubts, encouragement and invitations for interviews.

One Ônibus Hacker event which recently took place in August 2015 at LabHack in the House of Representatives was HackDay, which involved twenty-one hack activists who went to Brasília to develop political education games and promote debates and conversations about transparency with politicians and students.

\section{Discussion}

This is not the place to list a chronology of all the projects undertaken by the THacker community, but it should be noted that for the purposes of this article, the projected websites and services aren't being examined with a traditional design analysis for digital platforms. In classic cases of digital design, user needs are evaluated for ergonomics, usability and the quality of the experience. This kind of analysis is derived 
from digital design methodologies dealing with interfaces, user interactions and user experience evaluations (BUXTON, 2007; GOODWIN, 2009; GARRETT, 2011). In a study focused on the city and its citizens, complementary methods were necessary, as shown before. These involve also group's engagement, basic motivations and guiding mission. These themes have recently been discussed in the context of design for social innovation (MANZINI, 2015), service design (POLAINE, LØVLIE, 2013) and funding for urban projects (VANZELLA, 2014). That is why also, in our research, we articulated THackers actions to authors focused on Open Data, Transparency and e Govenrnment.This paper presents actions and ways of understanding actions of the THacker community. It acts a case study for a broader research of applications and services oriented towards citizenship solutions for the city and a better life named networked citizenship (cidadania em rede). In our research we look into government bodies working in collaboration with private initiatives, startups, collectives and individuals.

After two years of research we could identify that THacker, trough digital technologies has had impact leading individuals and government to act on relevant issues when focusing on two axes: monitoring (and sharing) and proposing solutions. Oriented towards citizenship this community has projects in collaboration with government bodies and other collectives by monitoring and sharing: reporting about unmet needs to press governments into action, and to supply authorities with useful information. By proposing solutions trough applications (and related services and products) that enable communities to act directly on local problems (strengthening civil society) as well as to help government to implement and monitor more efficiently projects in these areas.

The Transparência Hacker community was founded in 2009 with the clear mission of opening up access to public government data to all citizens and encouraging civic participation through the use of the internet. As of the middle of September 2015, it has 1,786 members and almost 6,900 topics posted in its forum. It's made up of people from many different cities and all walks of life who share an interest in the transparency of government data and related actions that may be taken following the principles of collaboration and sharing to promote civic participation and civil rights. Its members call themselves civic activists and hackers. The most active member, Pedro Markun, has made almost 4,900 posts since the forum began its activities. THacker has an important presence on the internet with its websites and digital initiatives as well as outside of the internet in various cities in this country. Examples of this are the Ônibus Hackers and LabHacks of Brasilia and São Paulo.

It's apparent that many projects haven't been updated over the last few years, which means that they are only registered in Transparência Hacker's open group or in our database. Our hypotheses for these occurrences are: a) there is no updating and maintenance team; b) these projects depend on public or other partners and sponsors c) these projects lack financial and strategic implementation planning; d) group members are focused on other projects or issues.

The tendency to initiate actions and create apps and services is expanding. Many are being created by startups and groups working in collaboration with government agencies. Many are adopted by government agencies. The community today seeks to experiment with free technology, exchange knowledge, raise political consciousness and encourage the exercise of every citizen's rights, all under the guiding principles of autonomy and freedom of expression. The motivations and setting of these groups which dream up and build these projects are a rich source of research material for engagement, motivation and project sustainability models.

The selected case study, a two year investigation of hacker activism through continuous actions taken to i) increase access to public/government data, ii) display it in an accessible form and iii) raise the consciousness of communities and municipalities) stimulates a discussion of the information access law and its influence on the Brazilian context. The description of protocols used for data transparency in the governmental context (Portal de Dados Abertos - Open Data Portal), such as the 8 principles of the OGD or W3C's 5 star scheme should be seen as protocols already disseminated as eGovernment principles acting in Brazil to increase citizenship and collaboration.

Recording the history of and describing how initiatives related to civic participation based on sharing, and in particular hackactivism in its online and offline forms, have fared as well as communities, e.g. the case of Ônibus Hacker (Hacker Bus).

The creation of a repository of information about THacker and its initiatives that can no longer be found on the internet show how significant it is to study recent events despite the fact that they are historically significant. The importance of the database is presented, given that many of the community's initiatives have not been updated and have been abandoned. However, this does not signify that they have not been effective, because they may have been the result of short-term actions with limited objectives. Examples of this are the websites alagamentos SP (SP flooding) and ferramentas hacker (hacker tools).

Our study can trace current examples of projects that deal with contemporary issues such as civil rights, civic participation, public governance, education and the capacity to exercise a citizen's rights through actions and interventions on the internet and outside of it to the academic context of design and urban studies. Further, we try to update design methods within academic contexts considering the context of fully informational government (eGovernment), which requires more and more participative decisions and bottomup contributions from its citizens.

\section{References}

ALÓ, C. C. (2009). Uma Abordagem para Transparência em 
Processos Organizacionais Utilizando Aspectos. Tese de Doutorado. Programa de Pós-Graduação em Informática da PUCRio. (An Approach towards Transparency in Organized Processes Using Aspects. Doctoral Thesis. Post-Graduate Program in Information Technology at PUC-Rio) Available at: http://wwwdi.inf.puc-rio.br/ julio/tese-cappelli.pdf Accessed on 9/7/2015.

BRAGA, M. V. A. (2011). A Auditoria Governamental como Instrumento de Promoção da Transparência (Governmental Auditing as an Instrument to Promote Transparency). in IV Congress CONSAD, Brasília-DF: May 25 - 27, 2011. Available at: https://bvc.cgu.gov.br/handle/123456789/3676 Accessed on 9/7/2015.

BERNERS-LEE (2006). Linked Data. 7/27/2006. Available at: http://www.w3.org/DesignIssues/LinkedData.html Accessed on $9 / 7 / 2015$.

BUXTON, B. (2007). Sketching user experiences. San Francisco: Morgan Kaufmann.

CAPPELLI, C.; LEITE, J. C. S. P; ARAUJO, R. M. (2010). A importância de um modelo de estágios para avaliar transparência (The importance of a stage model to evaluate transparency). Revista do Tribunal de Contas do Município do Rio de Janeiro. (45, 09, 2010). Rio de Janeiro, RJ.

CAPPELLI, C., LEITE, J. C. S. P. (2008). Transparência de Processos Organizacionais (The Transparency of Organizational Processes). Universidade Federal Fluminense, LATEC. II Simpósio Internacional de Transparência nos Negócios (International Symposium on Transparency in Business). http://www.latec. uff.br/transparencia/documentos/anais_transparencia2/ T6_0115_0129.pdf Accessed on 9/7/2015.

DARBISHIRE, H. (2009). ProactiveTransparency: The future of the right to information? Working Paper prepared for the World Bank Access to Information Program. Washington, DC. Available at: http://siteresources.worldbank.org/Extgovacc/ Resources.DarbishirePT.pdf . Accessed on 9/7/2015.

EAVES, D. (2009). The Three Laws of Open Government Data. Post from 9/30/2009. Available at: http://eaves.ca/2009/09/30/ three-law-of-open-government-data/. Accessed on 9/7/.2015.

FELIX, L. in M. \& HANDORF, W. (2011) Proactive Transparency: What has been done in Brazil? Minerva Program 2011, IBI - The Institute of Brazilian Business \& Public Management Issues,George Washington University, Washington, DC. Available at: http://www.gwu.edu/ ibi/minerva/Spring2011/ Leodelma_Felix.pdf Accessed on 9/7/2015.

GARRETT, J. J.(2011). The Elements ou User Experience. Berkeley: New Riders.

GOODWIN, K. (2011). Design for the digital age. How to create human-centered products and services. Indianopolis: Wiley Publishing.

HOLZNER, B. \& HOLZNER L. (2006). Transparency in Global Change: The Vanguard of the Open Society. Pittsburgh: University of Pittsburgh Press.

LIRA, L. \& SVAB, H. (2012). Já fez seu pedido de informação hoje? (Have you made your information request today?) in Canal iBase, 5/25/2012.

Available at: http://www.canalibase.org.br/ja-fez-seu-pedido- de-informacao-hoje/ Accessed on 9/7/2015.

LIRA, L. (2013). Ônibus Hacker: Liane Lira at TEDxUFG. Video. 9/16/2013. Available at: https://www.youtube.com/ watch?v=o2ARDpEgEOQ Accessed on 9/9/2013.

MANZINI, Ezio. Design, when everybody designs. Boston, The MIT Press, 2015.

MARKUN, P. \& SILVA, D. (2009). Programação do $1^{\circ}$

Transparência Hackday (Program for the First Transparency Hackday). Available at: http://pt.slideshare.net/esferamobi/ transparencia-hackday-proposta Accessed on 9/7/2015.

MARKUN, P. \& SILVA, D. (2009).Site com declaração sobre THacker. Available at: http://blog.esfera.mobi/transparenciahacker/ Accessed on 9/7/2015.

MARKUN, P. (2012). A ideologia por trás da Transparência Hacker (The Ideology behind Transparency Hacker). Interview in Canal iBase, 2/17/2012. Available at: http://www.canalibase. org.br/a-ideologia-por-tras-da-transparencia-hacker/ Accessed on $9 / 7 / 2015$.

POLAINE, A., LøVLIE, L. \& REASON, B. (2013). Service Design: From Insight to Implementation. New York: Rosenfeld Media.

SILVA, M. D. C. (2011). Exercício Pleno da Cidadania: A transparência como instrumento de controle social (Full Civic Participation: Transparency as an Instrument of Social Control) in IVCongressoCONSADdeGestão Pública.Panel44/147. Available at: http://www.sgc.goias.gov.br/upload/arquivos/2011-06/ painel_44-155_156_157.pdf Accessed on 9/7/2015.

VANZELLA, R. (2014). Financiamento de Projeto Urbano. IN LAZARRINI, S. G (org. ) Financiamento da inovação urbana: novos modelos. São Paulo: Bei Editora (96-111).

\section{Websites}

The Annotated 8 Principles of Open Government Data. Dec. 7-8, 2007. Available at: http://opengovdata.org. Accessed on 9/7/2015.

Article $8^{\circ}$, $\S 3^{\circ}$ of Common Law 12,527/ 2011 of the Brazilian Federal Constitution. Available at: http://www.planalto.gov. br/ccivil_03/_ato2011-2014/2011/lei/112527.htm. Accessed on 9/7/2015.

Portal de Dados Abertos (Open Data Portal). Available at: http:// dados.gov.br. Accessed on 9/7/2015

Ônibus Hacker Blog. Available at: https://groups.google.com/ forum/\#!forum/onibushacker Accessed on 9/7/2015

Revista LabHacker (LabHacker Magazine). Available at: http:// labhackercd.net/assets/files/revista_labhacker.pdf Accessed on 9/7/2015

Lei de Acesso à Informação (Information Access Law). Available at: http://www.planalto.gov.br Accessed on 9/7/2015

Tools for Hacker Dados (Hacker Data). Available at: http:// thacker.diraol.eng.br/ferramentas/ Accessed on 9/7/2015. Study developed at LabVisual | FAUUSP. It begun in 2013 and is associated to research "Cidadania em Rede (Civic Participation on the Internet)". Acknowledgements: Erica Ide, research and images; Maria Beatriz Camargo, research and images; Program Aprender com Cultura e Extensão at USP: Fellow Bruna Lopes Ferreira, database. 